\title{
Prevalência de suínos portadores de Salmonella sp. ao abate e contaminação de embutidos tipo frescal ${ }^{*}$
}

\author{
Prevalence of Salmonella carrier pigs at slaughter and contamination of fresh pork sausage \\ Sandra Maria Ferraz Castagna', Patrícia Schwarz' ${ }^{1}$ Cláudio Wageck Canal $^{2}$ \\ \& Marisa Ribeiro de Itapema Cardoso²
}

\begin{abstract}
RESUMO
O abate de suínos portadores de Salmonella sp. é considerado o primeiro ponto crítico para a contaminação do produto final. O risco representado por esses animais tende a aumentar quando a bactéria está presente em porções da carcaça que chegam até o consumidor. No presente estudo, buscou-se verificar a associação da prevalência de suínos portadores de Salmonella sp. ao abate e a contaminação da massa utilizada na fabricação de embutidos tipo frescal, produzida com matériaprima proveniente destes animais. Numa primeira etapa, foram realizadas três visitas a um frigorífico, onde foram coletados "pools" de linfonodos submandibulares/tonsilas (LT) e conteúdo intestinal (CI) de 16 animais em cada oportunidade. No dia subsequiente ao abate, foram coletadas 99 porções da massa, produzida com a carne dos animais abatidos, imediatamente antes do embutimento. Encontrou-se uma prevalência média de 83,33\% dos suínos portadores de Salmonella sp. ao abate, enquanto que $93,94 \%$ das amostras de massa de embutimento foram positivas. Os sorovares mais freqüentemente isolados foram Panama, Bredeney e Typhimurium. Numa segunda etapa, quantificou-se a bactéria em amostras positivas para Salmonella sp. Duas amostras, escolhidas aleatoriamente na quarta coleta, apresentaram 93 NMP/g e $150 \mathrm{NMP} / \mathrm{g}$ de $S$. Bredeney. Por outro lado, na quinta coleta, as duas amostras escolhidas apresentaram $<3 \mathrm{NMP} / \mathrm{g}$, respectivamente, de $S$. Typhimurium e $S$. Mbandaka. Os resultados do presente estudo demonstraram que a presença de Salmonella sp. em linfonodo submandibular/tonsila esteve associada com a contaminação da massa para embutimento. Por outro lado, a quantidade de Salmonella sp. presente no produto final esteve abaixo da dose infectante comumente proposta para humanos.
\end{abstract}

Descritores: Salmonella sp., suíno, linfonodos submandibulares, tonsilas, embutidos.

\begin{abstract}
The slaughter of Salmonella carrier pigs is considered the first critical point for the contamination of pork products. The risk represented by positive animals tends to increase, when this pathogen is found in carcass portions consumed by the population. The aim of this study was to assess the implication of the Salmonella positive pigs prevalence at slaughter on the contamination of ground meat used for fresh sausage production. In a first phase, mandibular lymph node/tonsil pools (LT) and intestinal contents (CI) of 16 animals where collected in each one of three samplings conducted at an abattoir in Southern Brazil. On the day after, 99 samples of the ground meat, produced with carcass parts of pigs slaughtered in the previous day, were collected immediately before the casing. The mean prevalence of Salmonella carrier pigs at slaughter was $83.33 \%$, while $93.94 \%$ of the ground meat samples were positive. The most prevalent serovars were Panama, Bredeney, and Typhimurium. In a second phase, a Salmonella quantification protocol was applied on ground meat positive samples collected on two additional sampling days. Two samples randomly chosen at the fourth sampling presented $93 \mathrm{MPN} / \mathrm{g}$ and $150 \mathrm{MPN} / \mathrm{g}$ of $S$. Bredeney. On the other hand, two samples from the fifth sampling presented <3 MPN/g, respectively, of $S$. Typhimurium and $S$. Mbandaka. Theses results demonstrated that the slaughter of Salmonella positive pigs implicated on the fresh pork sausage contamination. On the other hand, the amount of Salmonella found in ground meat samples was lower than the infective dose commonly proposed for humans.
\end{abstract}

Key words: Salmonella sp., swine, mandibular lymph nodes, tonsils, fresh pork sausage.

* Parte da Tese de Doutorado do primeiro autor. ${ }^{1}$ Programa de Pós-graduação em Ciências Veterinárias (PPGCV) da Faculdade de Veterinária (FaVet), Porto Alegre, Universidade Federal do Rio Grande do Sul (UFRGS). ${ }^{2}$ FaVet - UFRGS, Porto Alegre. CORRESPONDÊNCIA: M.R.I.Cardoso [mcardoso@vortex.ufrgs.br ; FAX: +51 3316 7305] 
A Salmonella é mundialmente reconhecida como um dos principais causadores de infecções de origem alimentar. Os alimentos implicados em surtos, geralmente, são produtos de origem animal contaminados, oriundos de animais portadores assintomáticos ou contaminados durante o processamento [22]. A demanda crescente de derivados suínos tipo frescal pode significar um aumento do risco destes produtos participarem de surtos de salmonelose em humanos. Estes produtos, por não sofrerem processamento pelo calor que propiciaria a eliminação de microrganismos patogênicos, têm sua qualidade microbiológica dependente da ausência dos mesmos na matéria-prima. Com isso, a entrada de um alto número de animais portadores de Salmonella sp. no frigorífico faz com que aumente o risco de presença da bactéria no produto, uma vez que esforços adotados na linha de processamento para evitar a contaminação cruzada podem não ser suficientes para garantir a qualidade final. Em estudo prévio, encontrou-se uma alta prevalência de suínos portadores assintomáticos de Salmonella sp., tanto no trato gastrintestinal, como em linfonodos submandibulares e tonsilas [7]. O risco que este isolamento representa vai, desde a contaminação cruzada durante o processamento até a presença da bactéria em porções da carcaça empregadas na fabricação de embutido e carne mecanicamente separada. Entretanto, o real impacto do isolamento de Salmonella sp. em suínos abatidos na contaminação do produto final permanece por ser investigada. Desta forma, o objetivo do presente estudo foi verificar a associação da prevalência de suínos portadores de Salmonella sp. ao abate e a contaminação da massa utilizada na fabricação de embutidos tipo frescal, produzida com matéria-prima proveniente destes animais.

\section{MATERIAIS E MÉTODOS}

Este estudo foi conduzido em um frigorífico sob Inspeção Federal, localizado no Estado do Rio Grande do Sul, onde a prevalência de Salmonella sp. em suínos abatidos havia sido determinada anteriormente [5]. Foram realizadas cinco visitas, entre agosto de $2001 \mathrm{e}$ abril de 2002.

\section{AMOSTRAGEM}

O número de amostras para a determinação da prevalência de animais positivos no dia de abate foi calculado, levando em consideração uma prevalência esperada de $80 \%$ [7]; uma precisão de 10\%, 95\% de nível de confiança e um abate diário de 2.000 animais [28]. A primeira carcaça foi selecionada por sorteio e as demais foram escolhidas em um intervalo calculado a partir do número previsto de animais a serem abatidos pelo número de amostras a serem coletadas $(n=16)$, de forma que fossem amostrados animais de quatro lotes diferentes. Foram coletados "pools" de linfonodos submandibulares/tonsilas (LT) e um fragmento de intestino (CI) para coleta do conteúdo. As amostras foram colocadas em sacos plásticos individuais identificados e conservadas sob refrigeração até chegarem ao laboratório.

As amostras de produto final foram coletadas no dia subseqüente, uma vez que as carcaças permaneciam por 24 horas na câmara fria antes de serem processadas. Foram coletadas amostras de massa para embutimento, composta da carne de animais dos 4 lotes amostrados e dos demais animais abatidos no mesmo dia. Para o cálculo do número de amostras, foi considerado um intervalo de confiança de $95 \%$ e uma prevalência detectável de 3\%, o que resultou na coleta de 99 alíquotas de aproximadamente 30 gramas de massa. As amostras coletadas foram processadas em "pool" de três amostras, após decorrido o tempo usual de maturação de $18 \mathrm{~h}$ sob refrigeração.

$\mathrm{Na}$ quarta e quinta coleta, este protocolo de amostragem foi alterado, para que pudesse haver o processamento individual das amostras, sendo coletadas 22 alíquotas de produto final. Os demais procedimentos foram conduzidos como descrito.

\section{Protocolo de isolamento de Salmonella sp.}

As amostras coletadas (25g) foram submetidas a protocolo de isolamento previamente descrito [20]. $\mathrm{Na}$ quarta e quinta coletas, o restante da amostra foi mantida sob refrigeração até o resultado de identificação presuntiva. As colônias típicas e suspeitas de Salmonella sp. foram identificadas através de suas características morfológicas e bioquímicas, conforme metodologia de rotina [16]. As bactérias presuntivamente identificadas como Salmonella foram submetidas a sorologia com soro polivalente (Somático - PROBAC). Quando positivas, as amostras foram encaminhadas ao Instituto Oswaldo Cruz (Rio de Janeiro) para sorotipificação definitiva.

\section{Quantificação de Salmonella sp. no produto final}

Duas amostras escolhidas aleatoriamente entre as positivas na quarta e quinta coletas foram sub- 
metidas ao protocolo de quantificação. Esta técnica foi realizada a partir do método do Número Mais Provável (NMP) [9], com modificações. De cada amostra positiva, $25 \mathrm{~g}$ foram homogeneizadas em $225 \mathrm{~mL}$ de água peptonada tamponada $1 \%$. Esta amostra diluída foi, a seguir, fracionada em três alíquotas de $50 \mathrm{~mL}$, três alíquotas de $5 \mathrm{~mL}$ e três alíquotas de $0,5 \mathrm{~mL}$. Nas alíquotas de $0,5 \mathrm{~mL}$, foi acrescentado $5 \mathrm{~mL}$ de água peptonada $1 \%$ para propiciar um volume mínimo de meio de cultura que permitisse o crescimento bacteriano. Todas as alíquotas foram incubadas a $37^{\circ} \mathrm{C}$ por $18 \mathrm{~h}$ e, a seguir, submetidas a enriquecimento seletivo em caldo Rappaport-Vassiliadis e isolamento em ágar XLT4 e Verde Brilhante-Lactose-Sacarose. A identificação de Salmonella sp. foi realizada como descrito [16]. O número mais provável de Salmonella sp. no produto final foi calculado pela tabela do NMP [3], a partir do número de alíquotas que apresentaram crescimento da bactéria.

\section{Análise Estatística}

Os resultados de prevalência nos animais e no produto final foram avaliados estatisticamente pelo Teste Exato de Fisher do programa estatístico SPSS [26].

\section{RESULTADOS}

\section{Prevalência de Salmonella sp. em suínos abatidos e na massa para embutimento}

Encontrou-se uma prevalência média de 83,33\% dos suínos portadores de Salmonella nos linfonodos submandibulares/tonsilas e conteúdo intestinal, com valores variando entre $81,25 \%$ e $87,50 \%$, nas três primeiras coletas (Tabela 1). Avaliando-se a presença de Salmonella em diferentes amostras coletadas de uma mesma carcaça na linha de abate (Tabela 2), observouse que, dos 40 animais portadores, $21(52,5 \%)$ eram positivos em LT e CI simultaneamente. Em 16 (40\%) houve isolamento apenas a partir de LT , enquanto em 3 (7,5\%) apenas a partir de CI. Desta forma, encontrouse a presença de Salmonella sp. em 92,5\% das amostras de LT analisadas. Por outro lado, a prevalência média encontrada no produto final fabricado com matéria-prima oriunda destes animais foi de 93,94\%, variando de 85 a 100\% nas três primeiras coletas (Tabela 1).

\section{Sorotipificação das amostras}

Observou-se uma grande diversidade de sorovares, tanto nos animais, como no produto final
Tabela 1. Prevalência de Salmonella sp. (\%) de acordo com o número (n) de suínos analisados e em alíquotas de massa para embutimento (n) coletadas em três visitas a um frigorífico do Rio Grande do Sul, em 2001-2002.

\begin{tabular}{cccccc}
\hline \multirow{2}{*}{ Coleta } & \multicolumn{2}{c}{$\begin{array}{c}\text { Animais } \\
\text { positivos }\end{array}$} & \multicolumn{2}{c}{$\begin{array}{c}\text { Massa para } \\
\text { embutido positiva }\end{array}$} & \multirow{2}{*}{$\mathbf{P}(\mathbf{9 5 \% )})$} \\
\cline { 2 - 5 } & $\mathrm{n}$ & $\%$ & $\mathrm{n}$ & $\%$ & \\
\hline I & 13 & 81,25 & 32 & 97 & 0,096 \\
II & 13 & 81,25 & 28 & 85 & 1,000 \\
III & 14 & 87,50 & 33 & 100 & 0,102 \\
\hline
\end{tabular}

Tabela 2. Amostras positivas para Salmonella sp. em "pool" de linfonodos submandibulares e tonsilas (LT) e conteúdo intestinal (CI) de suínos ao abate.

\begin{tabular}{cccc}
\hline Coleta & $\begin{array}{c}\text { Linfonodo } \\
\text { Submandibular/Tonsila }\end{array}$ & $\begin{array}{c}\text { Conteúdo } \\
\text { Intestinal }\end{array}$ & LT+Cl \\
\hline I & 8 & 2 & 3 \\
II & 5 & 1 & 7 \\
III & 3 & - & 11 \\
Total & 16 & 3 & 21 \\
\hline
\end{tabular}

(Tabela 3). Foram identificados oito diferentes sorovares nos 60 animais portadores, sendo os mais encontrados: Panama (29,9\%), Bredeney $(24,1 \%)$ e Typhimurium $(20,7 \%)$. Na maioria das vezes, as amostras de Salmonella isoladas de CI e LT pertenciam a sorovares diferentes. Apenas em 9 animais houve concordância entre os sorovares presentes nestes dois materiais, sendo encontrados os sorovares Panama $(n=7)$, Bredeney $(n=1)$ e Typhimurium $(n=1)$. Os sorovares encontrados nos animais positivos, com exceção do sorovar Orion, também estavam presentes nas amostras da massa para embutimento.

No produto final, predominaram os sorovares Bredeney (33,8\%), Saint-Paul (22,0\%), Panama $(12,6 \%)$ e Typhimurium $(11,0 \%)$. Os sorovares Enteritidis e Saint-Paul foram encontrados exclusivamente em amostras de massa para embutimento.

Analisando as coletas individualmente, foi possível verificar que os sorovares encontrados nos animais nem sempre coincidiram com aqueles encontrados no produto final (Tabela 3). Apenas na segunda e quarta coletas houve coincidência no sorovar predominante, respectivamente, Panama e Bredeney. Por outro lado, na primeira coleta, os sorovares mais encontrados nos animais foram Typhimurium e 
Tabela 3. Sorovares de Salmonella identificados em suínos ao abate e massa para embutido tipo frescal, em cinco coletas realizadas em frigorífico do Rio Grande do Sul, no período de 2001-2002.

\begin{tabular}{|c|c|c|c|c|}
\hline \multirow{2}{*}{ Coleta } & \multirow{2}{*}{ Sorovar } & \multicolumn{2}{|c|}{ Número de isolados } & \multirow{2}{*}{ Total } \\
\hline & & Animais & Embutidos & \\
\hline \multirow{8}{*}{1} & Agona & 1 & - & 1 \\
\hline & Bredeney & 5 & 5 & 10 \\
\hline & Derby & 1 & - & 1 \\
\hline & Mbandaka & 2 & 2 & 4 \\
\hline & Typhimurium & 6 & - & 6 \\
\hline & Salmonella sp. & 1 & - & 1 \\
\hline & Panama & - & 2 & 2 \\
\hline & Saint-paul & - & 23 & 23 \\
\hline \multirow{8}{*}{$\|$} & Bredeney & 2 & 3 & 5 \\
\hline & Derby & 5 & 1 & 6 \\
\hline & Mbandaka & - & 7 & 7 \\
\hline & Minnesota & 2 & - & 2 \\
\hline & Panama & 11 & 8 & 19 \\
\hline & Saint-paul & - & 5 & 5 \\
\hline & Salmonella sp. & - & 1 & 1 \\
\hline & Typhimurium & - & 3 & 3 \\
\hline \multirow{9}{*}{ III } & Agona & - & 1 & 1 \\
\hline & Bredeney & 5 & 12 & 17 \\
\hline & Derby & 1 & 2 & 3 \\
\hline & Enteritidis & - & 2 & 2 \\
\hline & Mbandaka & 1 & 1 & 2 \\
\hline & Orion & 5 & - & 5 \\
\hline & Panama & 9 & 6 & 15 \\
\hline & Salmonella sp. & - & 1 & 1 \\
\hline & Typhimurium & 4 & 8 & 12 \\
\hline \multirow{6}{*}{ IV } & Agona & 1 & - & 1 \\
\hline & Bredeney & 9 & 15 & 24 \\
\hline & Derby & - & 4 & 4 \\
\hline & Mbandaka & 1 & - & 1 \\
\hline & Minnesota & 1 & 2 & 3 \\
\hline & Typhimurium & 2 & - & 2 \\
\hline \multirow{5}{*}{ V } & Bredeney & - & 8 & 8 \\
\hline & Mbandaka & - & 1 & 1 \\
\hline & Panama & 6 & - & 6 \\
\hline & Salmonella sp. & - & 1 & 1 \\
\hline & Typhimurium & 6 & 3 & 9 \\
\hline Total & & 87 & 127 & 214 \\
\hline
\end{tabular}

Bredeney, enquanto que, no produto final, predominou o sorovar Saint-Paul, que não foi encontrado em nenhuma amostra proveniente dos animais.

\section{Quantificação de Salmonella sp. no produto final}

Devido ao elevado percentual de produtos com presença de Salmonella sp., buscou-se avaliar o nível de contaminação através da quantificação da bactéria em amostras positivas escolhidas aleatoriamente na quarta e quinta coletas.

$\mathrm{Na}$ quarta e quinta coletas, a prevalência de animais positivos ao abate foi inferior às coletas anteriores, ficando, em ambos os casos, em $62,5 \%$. Apesar disto, na quarta coleta, 95,45\% das amostras de produto final tiveram presença de Salmonella sp. Na quinta coleta, houve um decréscimo nesta ocorrência, encontrando-se $63,6 \%$ de amostras positivas.

As duas amostras, escolhidas aleatoriamente na quarta coleta, tinham a presença de $93 \mathrm{NMP} / \mathrm{g}$ e $150 \mathrm{NMP} / \mathrm{g}$ de $S$. Bredeney. Por outro lado, na quinta coleta as duas amostras apresentaram $<3 \mathrm{NMP} / \mathrm{g}$, respectivamente, de $S$. Mbandaka e $S$. Typhimurium.

\section{DISCUSSÃO}

A alta prevalência de suínos portadores de Salmonella sp. encontrada no presente estudo confirmou resultados prévios obtidos no mesmo abatedouro $[5,7]$. Conforme anteriormente observado, a infecção dos rebanhos tende a ser um problema persistente nos sistemas de produção de suínos, uma vez que diversos fatores podem contribuir para a cadeia epidemiológica do agente, dificultando o seu controle [6].

No presente estudo, houve um alto índice de portadores em linfonodos submandibulares/tonsilas, os quais permanecem na carcaça após o abate por estarem aderidos à musculatura da cabeça e por serem de difícil remoção. Sendo assim, era de se supor que haveria a presença de Salmonella sp. no produto final. Efetivamente, a prevalência média encontrada no produto final fabricado com matéria-prima oriunda destes animais foi de $93,94 \%$, variando de 85 a $100 \%$ nas três primeiras coletas.

Em situações onde existe a entrada constante de animais positivos na linha de abate, é praticamente impossível evitar a contaminação cruzada de carcaças. Medidas de sanitização e boas práticas de fabricação contribuiriam com não mais que $10 \%$ de redu- 
ção dos índices de contaminação do produto final [4]. Corroborando com isto, observou-se que não houve diferença estatística significativa entre a prevalência de animais portadores de Salmonella sp. com aquelas encontradas no produto final nas três primeiras coletas do presente estudo. Entretanto, verifica-se que os índices de amostras positivas no produto final sempre foram superiores aqueles encontrados nos animais, o que reflete a amplificação da contaminação durante a manipulação do produto durante o corte, desossa e moagem. Este fato foi amplamente discutido em estudo conduzido na Holanda, em que estimou-se a ocorrência de Salmonella sp. entre 5 e $40 \%$ nos cortes suínos, enquanto que em embutidos, este índice chegaria até $70 \%$ [4].

Observou-se que os índices de embutidos positivos para Salmonella sp. encontrados em estudos anteriores também foram elevados. Na Alemanha, avaliou-se carne suína moída, encontrando uma prevalência de 75,3\% [24]. No México, foram encontrados $88,3 \%$ de embutidos positivos [11]. Por outro lado, no Rio de Janeiro, encontrou-se 10\% das amostras coletadas de lingüiça frescal de origem suína positivas para Salmonella sp., enquanto que, no Rio Grande do Sul, 5\% de salames coloniais amostrados foram positivos $[8,19]$.

No presente estudo, os sorovares Bredeney e Saint-Paul foram os mais encontrados no produto final. Apesar de todos os sorovares de Salmonella serem considerados potencialmente patogênicos para humanos, a maioria dos surtos têm sido relacionados a apenas alguns sorovares, sendo Enteritidis e Typhimurium os mais freqüentes [23]. No Brasil, os sorovares Typhimurium, Enteritidis, Infantis e Agona foram identificados em casos de infecção alimentar em humanos, sendo que, nos últimos anos, o sorovar Enteritidis têm sido o mais encontrado [10,17].

A presença concomitante de múltiplos sorovares, encontrada no presente estudo, havia sido verificada anteriormente tanto em granjas como em diferentes amostras coletadas de um mesmo animal [5,21]. Da mesma forma, uma grande diversidade de sorovares também foi encontrada por outros autores, que isolaram 34 diferentes sorovares de Salmonella em amostras de carne suína crua [13]. A ocorrência de sorovares distintos nos animais e no produto final, por sua vez, pode ser explicada pela existência de diferentes origens de contaminação, relacionadas tanto à multiplicidade de sorovares presentes nos lotes de animais, quanto a possíveis contaminações cruzadas durante o processamento.

Pela legislação brasileira, Salmonella sp. tem que estar ausente em $25 \mathrm{~g}$ da amostra de alimento [1]. Entretanto, existe uma dose infectante mínima para a ocorrência de doença em humanos, a qual varia de acordo com o sorovar e o nível de adaptação deste ao hospedeiro [17]. Os valores encontrados no presente estudo estiveram abaixo da dose infectante, $10^{5}-10^{7}$ unidades formadoras de colônia, usualmente citada para salmonelas não pertencentes ao grupo tifóide. Entretanto, deve-se considerar que, em alimentos com elevado conteúdo de gordura e proteína, a dose infectante pode vir a ser menor devido à proteção das células bacterianas, propiciada por esta matriz, contra o suco gástrico [18].

Em situações em que a lingüiça frescal de carne suína seja ingerida crua pela população, amostras contaminadas podem vir a ser uma fonte de infecção importante [14]. Por outro lado, em estudo realizado na Dinamarca, observou-se que as contagens de Salmonella usualmente encontradas varia entre $<50$ até $400 \mathrm{ufc} / \mathrm{cm}^{2}$ de superfície de carcaça, havendo redução logarítmica na ordem de 2 a 3 log durante o processamento [2]. Considerando o costume da população brasileira de tratar pelo calor a lingüiça frescal antes do consumo, o risco que este produto pode vir a representar estaria mais relacionado à contaminação cruzada que pode ocorrer durante o preparo do alimento. Entretanto, a transferência desse microrganismo para outros alimentos, principalmente aqueles ingeridos crus, pode ser um importante fator determinante de surtos $[12,15]$.

É preciso considerar também que, além do risco de contaminação cruzada, a estocagem inadequada, permitindo que o microrganismo se multiplique até atingir a dose infectante, e o tratamento térmico inadequado podem determinar um aumento do risco que estes produtos representam [25]. Estudos que avaliem o risco microbiológico destes alimentos para o consumidor devem ser conduzidos para gerar um quadro mais claro deste problema de Saúde Pública. 


\section{CONCLUSÃO}

A prevalência elevada de suínos portadores de Salmonella sp. ao abate implicou na presença do microrganismo na massa utilizada na fabricação de embutidos tipo frescal, produzida com matéria-prima proveniente destes animais.
Agradecimentos. Ao CNPq pelo auxílio financeiro. À Dra. Eliane Falavina dos Reis, Departamento de Bacteriologia, Instituto Oswaldo Cruz, pela sorotipagem das amostras.

\section{REFERÊNCIAS}

1 ANVISA. 2001. Resolução $n^{\circ} 12$ ( 2 de janeiro de 2001).

2 Alban L., Olsen A.M., Nielsen B., Sorensen R. \& Jessen B. 2002. Qualitative and quantitative risk assessment for human salmonellosis due to multi-resistant Salmonella Typhimurium DT 104 from consumption of Danish dry-cured pork sausages. Preventive Veterinary Medicine. 52: 251-265.

3 BAM. 1998. Bacteriological Analytical Manual. Appendix 2: Most Probable Number determination from serial dilutions. 8th edn. Disponível na internet via http://www.cfsan.fda.gov.

4 Berends B.R, van Knapen F., Mossel D.A.A., Burt S.A. \& Snijders J.M.A. 1998. Impact on human health of Salmonella spp. on pork in The Netherlands and the anticipated effects of some currently proposed control strategies. International Journal of Food Microbiology. 44: 219-229.

5 Bessa M.C., Costa M. \& Cardoso M. 2004. Prevalência de Salmonella sp. em suínos abatidos em frigoríficos do Rio Grande do Sul. Pesquisa Veterinária Brasileira. 24: 80-84.

6 Blaha T.H. 2001. Pre-harvest food safety as integral part of quality assurance systems in the pork chain from "stable to table". In: Proceedings of the 4th International Symposium on the Epidemiology and Control of Salmonella in Pork (Leipzig, Germany). pp.7-13.

7 Castagna S.M.F., Bessa M.C., Costa M. \& Cardoso M. 2001. Antimicrobial resistance patterns of Salmonella sp. isolated from slaughtered pigs in the state of Rio Grande do Sul-Brasil. In: Proceedings of 4th International Symposium on the Epidemiology and Control of Salmonella in Pork (Leipzig, Germany). pp.412-414.

8 Chaves G.M.C., Gonçalves P.M.R., Franco R.M. \& Carvalho J.C.A.P. 2000. Avaliação bacteriológica de lingüiça frescal suína comercializada no Município do Rio de Janeiro, RJ. Higiene Alimentar. 4: 48-52.

9 Dufrenne J., Ritmeester V., Van Asch E.D., van Leusden F. \& de Jonge R. 2001. Quantification of the contamination of chicken and chicken products in the Netherlands whit Salmonella and Campylobacter. Journal of Food Protection. 64: 538-541.

10 Esper M.R.N.R., Freitas A.M., Fernandes S.A., Neme S.N., Tavechio A.T., Romão M.M. \& Café M.L. 1998. Salmonella: Sorotipos identificados das cepas isoladas de pacientes hospitalizados e não hospitalizados, na região de Presidente Prudente, SP, no período de 1978-1997. Revista do Instituto Adolfo Lutz. 57: 45-50.

11 Escartín E.F., Castilho A., Hinijosa-Puga A. \& Saldaña-Lozano J. 1999. Prevalence of Salmonella in churizo and its survival under different storage temperatures. Food Microbiology. 16: 479-486.

12 Escartín E.F., Lozano J.S. \& Garcia O.R. 2000. Quantitative survival of native Salmonella serovars during storage of frozen raw pork. International Journal of Food Microbiology. 54: 19-25.

13 Escartín E.F., Lozano J.S., García O.R., Gonzáles N.M. \& Torres J.A. 1995. Incidence and level of Salmonella serovars in raw pork obtained from Mexican butcher shops. Food Microbiology. 12: 435-439.

14 Giovannini A., Prencipe V., Conte A., Marino L., Petrini A., Pomilio F., Rizzi V. \& Migliorati G. 2003. Quantitative risk assessment of Salmonella spp. infection for the consumer of pork products in an Italian region. Food Control. 15:139144.

15 Gorman R., Bloomfield S. \& Adley C.C. 2002. A study of cross-contamination of food-borne pathogens in the domestic kitchen in the Republic of Ireland. International Journal of Food Microbiology. 76: 143-150.

16 Holt J. G., Krieg N. R., Sneath P. H., Stanley J. T. \& Williams S. T. 1994. Bergey's Manual of Determinative Bacteriology. 9th edn. New York: Williams \& Wilkims, 787 p. 
17 Jakabi M., Buzzo A.A., Ristori C.A., Tavechio A.T., Sakuma H., de Paula A.M.R. \& Gelli D.S. 1999. Observações laboratoriais sobre surtos alimentares de Salmonella sp. ocorridos na grande São Paulo, no período de 1994 a 1997. Revista do Instituto Adolfo Lutz. 58: 47-51.

18 Lax A.J., Barrow P.B., Jones P.W. \& Wallis T. S. 1995. Current perspectives in salmonellosis. British Veterinary Journal. 154: 351-337.

19 Lobo M.V., Ugalde M.G., Fries L.L.M. \& Kubota E.H. 2001. Avaliação microbiológica de salames coloniais comercializados no Município de Santa Maria-RS. Higiene Alimentar. 15: 57-61.

20 Michael G., Costa M. \& Cardoso M. 2003. Comparison of different seletive enrichment steps to isolate Salmonella sp. from feces of finishing swine. Brazilian Journal of Microbiology. 34:138-142.

21 Michael G.B., Simoneti R., Cardoso M. \& Costa M. 2002. Sorotipos de Salmonella isolados em uma propriedade de suínos de terminação no sul do Brasil. Ciência Rural. 32: 525-527.

22 Rostagno M.H. 2002. Epidemiologia e diagnóstico das infecções por Salmonella sp. em suínos. 56 f.. Belo Horizonte. Tese (Doutorado em Ciência Animal) - Escola de Veterinária, Universidade Federal de Minas Gerais.

23 Schlosser W., Hogue A., Ebel E., Rose B., Umholtz R., Ferris K. \& James W. 2000. Analysis of Salmonella serotypes from selected carcasses and raw ground products sampled prior to implementation of the pathogen reduction; Hazard Analysis and Critical Control Point final rule in the US. International Journal of Food Microbiology. 58: 107-111.

24 Sinell H.J., Pietzsch O., Klingbeil H. \& Benner M. 1990. Estimation of most probable number of Salmonella in retail samples of miced pork. International Journal of Food Microbiology. 11: 135-142.

25 Sojka W. J. \& Gitter M. 1961. Salmonellosis in pigs with reference to its public health significance. Veterinary Reviews and Annotations. 7: 11-28.

26 SPSS. 1998. Statistical Package for Social Sciences. Versão 8.0, Chicago

27 Swanenburg M., Urlings H. A. P., Keuzenkamp D. A. \& Snijders J.M.A. 1999. Tonsils of slaughtered pigs as marker sample for Salmonella positive pork. In: Proceedings of the 3rd International Symposium on the Epidemiology and Control of Salmonella in Pork (Washington, USA). pp.264-265.

28 Thursfield M. 1986. Veterinary Epidemiology. London: Ed. Butterworth, 280 p. 